\title{
A Surface Etching for Synthetic Diamonds with Nano-Thick Ni Films and Low Temperature Annealing
}

\author{
Jeongho Song, Yunyoung Noh, and Ohsung Song ${ }^{\dagger}$ \\ Department of Materials Science and Engineering, University of Seoul, Seoul 130-743, Korea \\ (Received May 6, 2015; Revised May 27, 2015; Accepted May 27, 2015)
}

\begin{abstract}
$\mathrm{Ni}(100 \mathrm{~nm}$ thick) was deposited onto synthesized diamonds to fabricate etched diamonds. Next, those diamonds were annealed at varying temperatures $\left(400 \sim 1200^{\circ} \mathrm{C}\right)$ for 30 minutes and then immersed in $30 \mathrm{wt} \% \mathrm{HNO}_{3}$ to remove the Ni layers. The etched properties of the diamonds were examined with FE-SEM, micro-Raman, and VSM. The FE-SEM results showed that the Ni agglomerated at a low annealing temperature $\left(\sim 400^{\circ} \mathrm{C}\right)$, and self-aligned hemisphere dots formed at an annealing temperature of $800^{\circ} \mathrm{C}$. Those dots became smaller with a bimodal distribution as the annealing temperature increased. After stripping the Ni layers, etch pits and trigons formed with annealing temperatures above $400^{\circ} \mathrm{C}$ on the surface of the diamonds. However, surface graphite layers existed above $1000^{\circ} \mathrm{C}$. The B-H loop results showed that the coercivity of the samples increased to 320 Oe (from $37 \mathrm{Oe}$ ) when the annealing temperature increased to $600^{\circ} \mathrm{C}$ and then, decreased to 150 Oe with elevated annealing temperatures. This result indicates that the coercivity was affected by magnetic domain pinning at temperatures below $600^{\circ} \mathrm{C}$ and single domain behavior at elevated temperatures above $800^{\circ} \mathrm{C}$ consistent with the microstructure results. Thus, the results of this study show that the surface of diamonds can be etched.
\end{abstract}

Key words : Synthetic diamond, Diamond etching, Nickel thin film, Vibrating sample magnetometer, Low temperature annealing

\section{Introduction}

S ynthetic diamond is a material having the same physicochemical properties as natural diamond produced in the nature, and has continued to be developed since the first commercial synthetic diamond was fabricated by GE company using a high-temperature, high-pressure method in $1954 .{ }^{1,2)}$ As diamond has a very high hardness and strength, excellent chemical resistance, high thermal conductivity along with a very low friction coefficient of about 0.05 in air, making it very suitable for cutting and grinding tools, etc. with its demand being increased drastically while being also utilized for lubrication recently. ${ }^{3)}$ In addition, with an increase in the demand for sapphire and silicon wafers as a substrate material for LED and other semiconductors, demand for synthetic diamond for use as an abrasive and a conditioner tool fabricate continues to be increased. ${ }^{4,5}$

To use synthetic diamonds for tools such as an abrasive as the primary application, a technique to fix the diamond to a metal frame or a part of jig is required. Typically used as a method to fix synthetic diamonds to grinding and cutting tools is mainly a method to fix the synthetic diamonds by plating a metal such as nickel or titanium which has excellent joining performance with diamond along with electrical

${ }^{\dagger}$ Corresponding author: Ohsung Song

E-mail : songos@uos.ac.kr

Tel : +82-2-6490-2410 Fax : +82-2-6490-2404 conductivity. More specifically, the diamonds are fixed by implementing plating after first positioning the synthetic diamonds to wire, grinding plate, and drill with a 3-dimensional curvature, etc. Herein, the method involves eventual fixing of nonconducting diamond which is not plated while a plating layer is formed starting with the metal body underneath to secure a given plating thickness so that a sturdy plating layer is formed in the periphery of the diamond as well. However, problems occurred where grinding quality was degraded when a defective part was produced upon plating as the plating layer covered a part or all of diamond due to conductive foreign objects on the diamond surfaces, or diamonds were dropped out during use due to an insufficient bond strength when the bond area between the base metal and the diamond was small.

To solve such existing problems, the surface parts of diamond are produced to be porous, which can give more excellent bond strength and higher durability compared with the existing products by increasing contact areas with the base metal underneath. Also, for the most ideal synthetic diamond to be used as a tool, it is advantageous to have as much exposure as possible of (100) plane orientation which has a relatively high hardness among diamond planes of the diamond. Otherwise, when a relatively weak (111) plane orientation is much exposed, problems exist where diamond can be destroyed during grinding and cutting processes. The function as an abrasive is improved if the (111) plane is removed through selective etching so that relatively more 
parts having the (100) plane are exposed.

For such reason, Ohashi et al. ${ }^{6}$ ) have recently made a report concerning surface etching of diamond for fabrication of porous diamond thin films, which involves synthesis of diamond with 100 orientation on a Si wafer having (100) plane by chemical vapor deposition method and subsequent vapor deposition of nano particles of $\mathrm{Co}, \mathrm{Ni}, \mathrm{Pt}$, etc. using a vacuum evaporator, followed by heat treatment at a high temperature above $800^{\circ} \mathrm{C}$.

In addition, Ohashi et $a l .{ }^{7)}$ have successfully fabricated porous diamonds by heat treatment at $1173 \mathrm{~K}$ after coating of $\mathrm{Fe}$ on the surface through sedimentation of $120 \mu \mathrm{m}$ class fine synthetic diamond in $\mathrm{Fe}\left(\mathrm{NO}_{3}\right)_{2}$ solution followed by drying.

However, graphitization of the surface can occur in both bulk and thin film-type synthetic diamonds when the diamonds are exposed to elevated temperatures above $800^{\circ} \mathrm{C}$, which is a thermodynamically stable domain for graphite. Such graphitization of synthetic diamonds should be actively prevented, since it fails to exhibit a sufficient grinding strength.

Therefore, in the present study, fabrication feasibility of porous diamonds having etch pits on the surface was to be affirmed by vapor deposition of $100 \mathrm{~nm}$-thick nickel on the surface part of synthetic diamonds with a homogeneous surface and implementation of heat treatment per temperature in a relatively a low-temperature section of $0 \sim 1200^{\circ} \mathrm{C}$.

\section{Experimental Procedure}

Diamond synthesis was implemented by using a hexagonal press capable of high-temperature, high-pressure treatment(Guilin Co., $\Phi 420$ model). By conducting a process under the condition of $5.5 \sim 6 \mathrm{GPa}$ in pressure, $1500 \sim$ $1600^{\circ} \mathrm{C}$ in temperature, 15 minutes in time after mixing graphite powders and Kovar metal catalyst powders containing $\mathrm{Ni} / \mathrm{Co} / \mathrm{Fe} / \mathrm{Mn}$ within a gasket loaded inside and then by placing it in a graphite heating element, synthetic diamond of $120 \mu \mathrm{m}$ class was finally prepared.

To fabricate porous diamonds, nickel with a high solid solubility for carbon was vapor deposited on the surface part of diamonds. For nickel vapor deposition, $100 \mathrm{~nm}$ of nickel was vapor deposited on the upper half face of diamonds at room temperature using a RF/DC magnetron sputter (SCSP3M3-380 model) and 99.99\% nickel target under the condition of $8.0 \times 10^{-6}$ torr of base pressure, 20 mtorr of working pressure, $70 \mathrm{~W}$ of RF power, $100 \mathrm{sccm}$ of $\mathrm{Ar}$ (99.9999 \%).

To subsequently fabricate porous diamonds, the diamonds with vapor deposition of nickel were subjected to heat treatment using a vacuum furnace (YL-TF-40/13 model) by raising temperatures at a rate of $5^{\circ} \mathrm{C} / \mathrm{min}$ to $400,600,800,1000$, $1200^{\circ} \mathrm{C}$, respectively, to be heat treated for 30 minutes and then air-cooled.

To remove a residual nickel layer on the surface of synthetic diamonds subjected to heat treatment, oxidation treatment was performed for 30 minutes by heating to $70{ }^{\circ} \mathrm{C}$ after feeding the diamond in $30 \% \mathrm{HNO}_{3}$ solution for final fabrication of diamonds with an etched surface.

To check for the microstructure after heat treatment and acid treatment following vapor deposition of nickel, an enlarged analysis was conducted using FE-SEM (Hitachi Co. S-4300 model). Microstructures of each heat-treated, acid-treated diamond were ascertained by magnification of 5,000 times under an acceleration voltage of $15 \mathrm{kV}$.

To check for the change in material properties of surface part of the diamonds, intrinsic peaks were confirmed by using micro-Raman (Unithink Co. UniRaman model). Analyses were conducted at a center value of $1300 \mathrm{~cm}^{-1}$ by irradiating $514 \mathrm{~nm}$ DPSS (diode pumped solid state) laser of $200 \mathrm{~mW}$ in power for an exposure value of 2 seconds after positioning the diamond sample on a glass substrate.

To check for the magnetic curve of the existing synthetic diamonds and the diamonds with vapor deposition of nickel along with the diamonds subjected to heat treatment, measurements were made by VSM (vibrating sample magnetometer, Lakeshore Co. 7400 series). Magnetic flux density $\mathrm{B}$ of each diamond was measured by measuring induced electromotive forces produced within the detection coil while \pm 5000 Oe of externally imposed magnetic field was applied after positioning of the sample. Coercivity was ascertained from the measured B-H loop.

\section{Results and Discussion}

Figure 1 shows FE-SEM images of diamond samples immediately following vapor deposition of $100 \mathrm{~nm}$-thick nickel on a synthetic diamond sample and after subsequent heat treatment of $\mathrm{Ni}$ thin film at varied temperatures of $400 \sim 1200^{\circ} \mathrm{C}$ for 30 minutes.

(a) shows a surface observation conducted immediately after vapor deposition of nickel on the synthetic diamonds where vapor deposition of a uniform nickel layer on the surface part of the synthetic diamond could be affirmed.

(b) shows a FE-SEM image after heat treatment of Ni thin film of (a) at $400^{\circ} \mathrm{C}$. Subgrains of about $1 \mu \mathrm{m}$ in average size are shown, which indicates the start of rearrangement of grains upon occurrence of nickel recrystallization even at a low temperature of about $400^{\circ} \mathrm{C}$. Such low-temperature recrystallization in metals has been reported only for nanoclass thin films, meaning that solid-solutioning of carbon by interdiffusion activity with the diamond underneath may be possible.

(c) shows an image after heat treatment at $600^{\circ} \mathrm{C}$, exhibiting grain growth at a higher temperature than $400^{\circ} \mathrm{C}$, which indicates preferential growth in some thin films to about $\sim 10 \mu \mathrm{m}$. Particularly, at such places as dotted line circular display part, steps are already being formed, resulting from solid-solutioning by nickel of carbon constituting the diamond underneath with formation of pit of about $1 \mu \mathrm{m}$, showing that such pit can grow further when subsequent heat treatment continues to be implemented.

(d) shows an analysis image of the microstructure after 


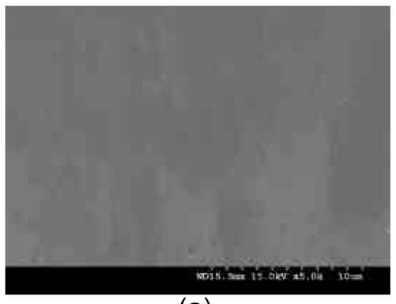

(a)

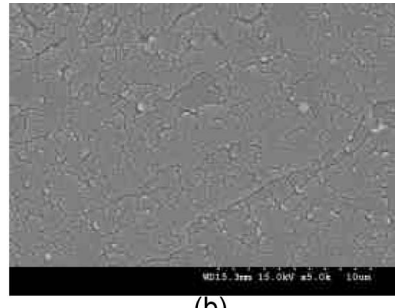

(b)

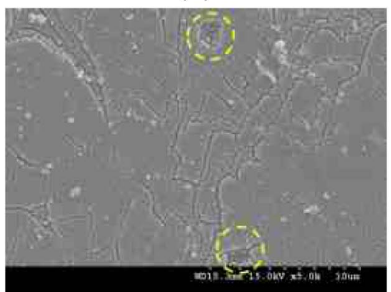

(c)

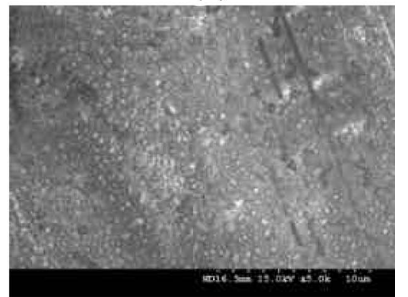

(d)

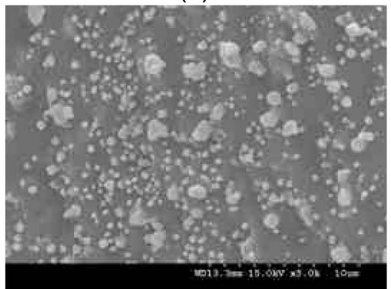

(e)

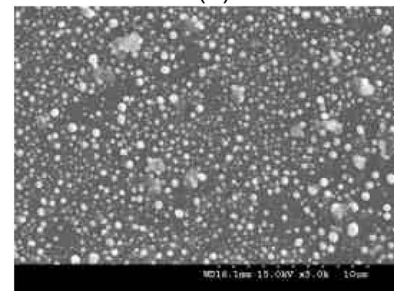

(f)

Fig. 1. FE-SEM images of synthetic diamonds (a) after deposition $100 \mathrm{~nm}-\mathrm{Ni}$, after heat treatment at temperatures of (b) $400^{\circ} \mathrm{C}$, (c) $600^{\circ} \mathrm{C}$, (d) $800^{\circ} \mathrm{C}$, (e) $1000^{\circ} \mathrm{C}$, (f) $1200^{\circ} \mathrm{C}$.

heat treatment at $800^{\circ} \mathrm{C}$. Unlike recrystallization and growth of nickel thin films observed in previous samples, formation could be affirmed of nickel dots of $298 \mathrm{~nm}$ in average size from nickel in the surface part of the diamond by a sufficient thermal energy. This was in good agreement with the results as reported by Kishimoto et $a l^{8)}$ that nickel thin films were agglomerated individually in an independent hemispherical form upon heat treatment at a sufficiently high temperature. Such abrupt hemispherical form of agglomeration phase shows stabilization into a hemispherical form to ultimately reduce surface tension by rapidly undergoing stages (b) and (c) when a sufficient energy such as $800^{\circ} \mathrm{C}$ is available, while hemispherical dots of such uniform size were affirmed to be distributed in a packed density of about $1.64 \mathrm{ea} / \mu^{2}$.

(e) shows an analysis image of the microstructure in the sample heat treated at $1000^{\circ} \mathrm{C}$, where nickel in average size of $945 \mathrm{~nm}$ and $369 \mathrm{~nm}$ agglomerates in the case of large hemispheres and small hemispheres, respectively, were affirmed to have been formed to a density of $1.58 \mathrm{ea} / \mu^{2}$, which was considered as having been agglomerated in an independent hemispherical form due to a sufficient energy as with the previous samples heat treated at $800^{\circ} \mathrm{C}$.

(f) shows an analysis image of the microstructure in the sample heat treated under the condition of $1200^{\circ} \mathrm{C}$ for 30 minutes. As with (d), nickel agglomerates were produced, and formed to an average size of $266 \mathrm{~nm}$ and an average

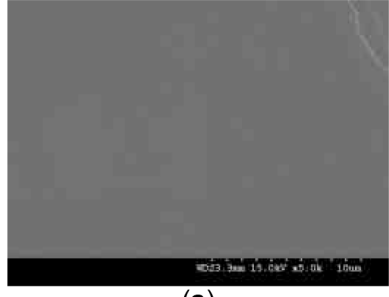

(a)

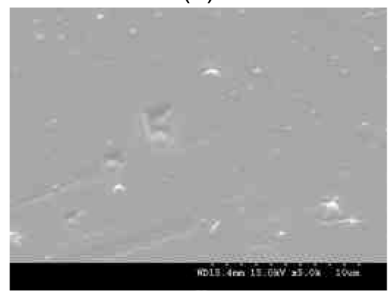

(c)

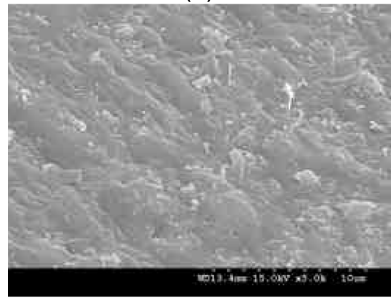

(e)

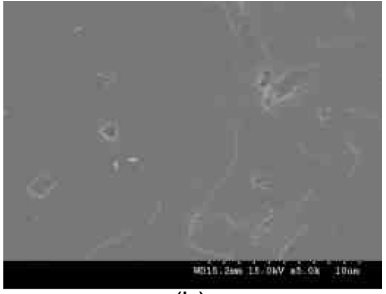

(b)

(d)

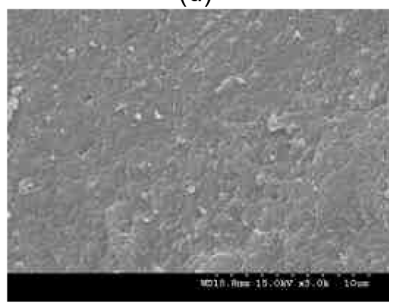

(f)

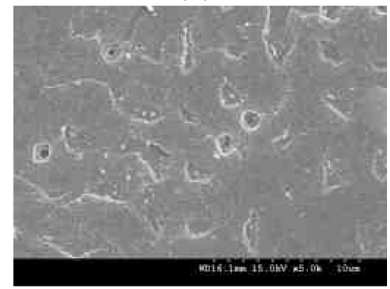

Fig. 2. FE-SEM images of the $\mathrm{Ni}$ coated on synthetic diamonds after heat treatment at temperatures of (a) $0^{\circ} \mathrm{C}$, (b) $400^{\circ} \mathrm{C}$, (c) $600^{\circ} \mathrm{C}$, (d) $800^{\circ} \mathrm{C}$, (e) $1000^{\circ} \mathrm{C}$, and (f) $1200^{\circ} \mathrm{C}$ (all samples are etched with $\mathrm{HNO}_{3}$ ).

density of $4.78 \mathrm{ea} / \mu^{2}$. This meant that more nucleus-generating sites were produced due to a higher thermal energy, which were characterized by diffusion at a higher rate along the surface to form more densely populated hemispheres.

Figure 2 shows an FE-SEM image of a diamond surface with the nickel layer removed by acid treatment of the synthetic diamond heat treated per temperature with vapor deposition of $100 \mathrm{~nm}$ nickel.

(a) shows an analysis image of the microstructure with the nickel layer removed without heat treatment after vapor deposition of nickel. Appearance of the observed surface being smooth can be affirmed in the same way as with the samples immediately following vapor deposition of nickel. This was considered attributable to no effects on change in the surface of even nitric acid treatment after deposition of nickel due to a high chemical resistance in the diamond characteristics.

(b) shows an analysis image after etching of the synthetic diamonds heat treated at $400^{\circ} \mathrm{C}$. Formation of pits with an average size of $1.40 \mu \mathrm{m}$ on the surface of the synthetic diamonds at a density of $0.028 \mathrm{ea} / \mu \mathrm{m}^{2}$ could be affirmed, which was a result of solid-solutioning in some nickel of the surface part of the synthetic diamonds composed of carbon.

(c) shows an analysis image of the microstructure after etching of the synthetic diamonds heat treated at $600^{\circ} \mathrm{C}$, where formation of pits with an average size of $1.51 \mu \mathrm{m}$ in the surface part of the synthetic diamonds to a density of 
$0.044 \mathrm{ea} / \mu \mathrm{m}^{2}$ could be affirmed. Also, production of triangular-shaped trigon etching pits could be ascertained.

(d) shows an analysis image of the microstructure after etching of the synthetic diamonds heat treated at $800^{\circ} \mathrm{C}$, where production of pits and trigon-shaped etching pits with an average size of about $1.62 \mu \mathrm{m}$ at a density of 0.084 $\mathrm{ea} / \mu \mathrm{m}^{2}$ could be affirmed. Also, a drastic increase in the number of produced pits could be affirmed in comparison with the previous samples, where agglomeration began at $800^{\circ} \mathrm{C}$ by a sufficient thermal energy as affirmed earlier in the results of Fig. 1, and the number was considered to have been drastically increased as a large amount of carbon was solid-solutioned in nickel accordingly.

(e) shows an analysis image of the microstructure after etching of the synthetic diamonds heat treated at $1000^{\circ} \mathrm{C}$. Pits and trigons produced in the previous samples could not be affirmed, and the surface part was affirmed to have become very rough. This was considered to have resulted from progress of graphitization in the surface part of the synthetic diamonds at high temperatures within a graphite stabilization domain even if heat treatment at $1000^{\circ} \mathrm{C}$ was conducted in a vacuum atmosphere. Also, such result was consistent with the report by Song et $a l .{ }^{9)}$ that the surface part of the diamond was grphitized upon high-temperature, high-pressure treatment in a graphite stabilization domain rather than a diamond stabilization domain in the P-T phase diagram of graphite and diamond. Furthermore, according to the visual analysis results, yellow synthetic diamonds appeared in a black grey color by vapor deposition of nickel and heat treatment in both cases of $800^{\circ} \mathrm{C}$ and $1000^{\circ} \mathrm{C}$ samples, while being changed to yellow and black colors, respectively, after acid treatment, meaning that graphitization had progressed in the case of $1000^{\circ} \mathrm{C}$ sample.

(f) shows an analysis image of the microstructure after etching of the synthetic diamonds heat treated at $1200^{\circ} \mathrm{C}$. In a similar way to the sample shown in (e), it can be affirmed that rough surfaces were exhibited as overall etching and graphitization rather than etching pits had progressed in the surface part by heat treatment .

Therefore, although effective fabrication of porosity for the surface part of diamonds was possible upon heat treatment below $800^{\circ} \mathrm{C}$, there was a problem where quality was rather degraded by surface graphitization upon heat treatment above $1000^{\circ} \mathrm{C}$.

Figure 3 shows a Raman graph analyzed after removal of vapor-deposited nickel by sedimentation in $30 \mathrm{wt} \% \mathrm{HNO}_{3}$ following heat treatment per temperature after vapor deposition of $100 \mathrm{~nm}$ nickel on the surface of synthetic diamonds. In the case of diamonds etched after treatment at $400 \sim 800^{\circ} \mathrm{C}$, a peak as the intrinsic Raman peak for diamonds could be affirmed at $1332 \mathrm{~cm}^{-1}$. However, at the temperature above $1000^{\circ} \mathrm{C}$ which is higher than the former a new Raman peak can also be affirmed at $1600 \mathrm{~cm}^{-1}$ in addition to the intrinsic peak of diamonds, which is $G$ peak intrinsic to graphite, ${ }^{10,11)}$ representing a progress of graphitization in the surface part of diamond above $1000^{\circ} \mathrm{C}$ as in the

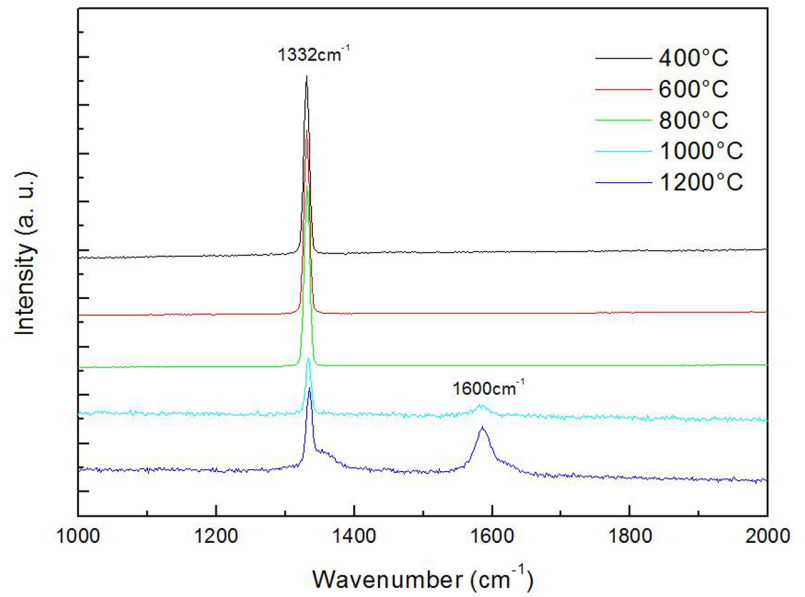

Fig. 3. Raman spectra of synthetic diamonds after etching with 30 wt $\% \mathrm{HNO}_{3}$.

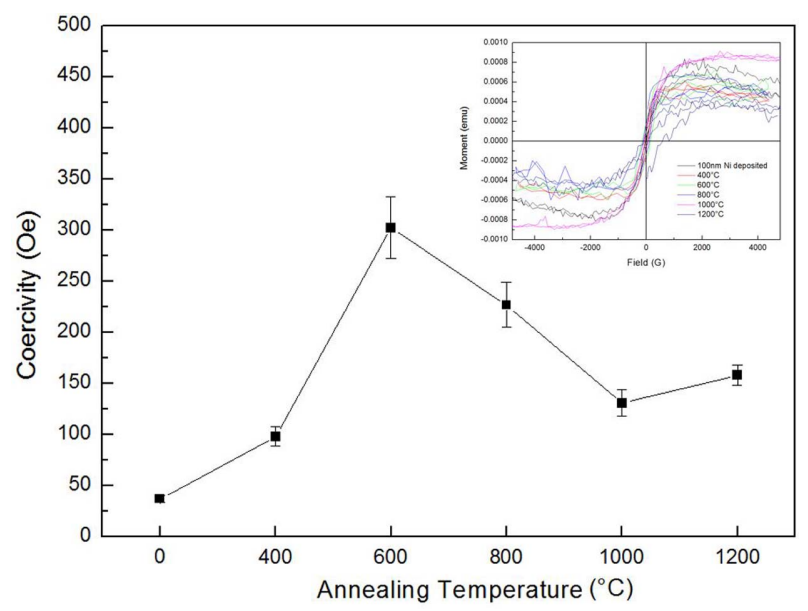

Fig. 4. Coercivity of the Ni-coated diamonds at different annealing temperatures. Inset shows the B-H loops with VSM.

FE-SEM result shown earlier. Therefore, heat treatment at temperatures higher than $1000^{\circ} \mathrm{C}$ in a vacuum atmosphere could be seen unsuitable for the use as an abrasive or machining agent due to graphitization of the diamond.

Figure 4 shows a graph for coercivity determined from B$\mathrm{H}$ loop which was inserted in the top right after heat treatment up to $1200^{\circ} \mathrm{C}$ of the synthetic diamonds with vapor deposition of $100 \mathrm{~nm}-\mathrm{Ni}$. Coercivity values at $0^{\circ} \mathrm{C}, 400^{\circ} \mathrm{C}$, $600^{\circ} \mathrm{C}, 800^{\circ} \mathrm{C}, 1000^{\circ} \mathrm{C}, 1200^{\circ} \mathrm{C}$ were shown to be $36.89,97.90$, $302.27,226.54,158.07$ Oe, respectively. The coercivity values can be affirmed to be increased up to $600^{\circ} \mathrm{C}$ by heat treatment, which results from start of agglomeration due to material transfer of nickel by thermal energy so that such agglomerates are operated as a pinning element for magnetic domains to act as a drag due to an external magnetic field. Meanwhile, coercivity can be affirmed to be decreased above $800^{\circ} \mathrm{C}$, which is attributed to the fact that spins can be easily switched as a result of an external magnetic field when nickel is agglomerated as fine spheres and each one of 
the agglomerates acts as a single domain. Such change in coercivity was in good agreement with the characteristics of microstructures as a function of heat treatment of nickel thin films shown earlier. Therefore, through a relatively simple measurement of B-H loop, a measure was provided allowing indirect determination of agglomeration extents for ferromagnetic substance of nickel and forecasting of the corresponding extents of etching in the surface part of diamonds, even without direct affirmation of the microstructures of a nickel layer.

\section{Conclusions}

In the present study, a process has been affirmed where porous diamonds can be fabricated by selective etching of the synthetic diamonds through a low-temperature heat treatment process after vapor deposition of $100 \mathrm{~nm}$ nickel on the surface part of the synthetic diamonds having a size of $120 \mu \mathrm{m}$ class. According to the FE-SEM results for the case of heat treated samples, formation of nickel agglomerates above $400^{\circ} \mathrm{C}$ was ascertained, while production of hemispherical fine nickel agglomerates above $800^{\circ} \mathrm{C}$ was affirmed. Also, according to the results of removing nickel layer by acid treatment, production of etch pits was most prevalent at $800^{\circ} \mathrm{C}$ without graphitization, while etching of the whole surfaces occurred along with graphitization of the surface part of synthetic diamonds at temperatures above $1000^{\circ} \mathrm{C}$. According to the VSM analysis results, good agreement was affirmed between change in coercivity as a function of temperature and change of nickel agglomerates. Therefore, indirect determination of the agglomeration extents for nickel in the surface part of the diamond was enabled through coercivity measurements.

\section{Acknowledgments}

This paper was supported by Basic Science Research Program through the National Research Foundation of Korea (NRF) funded by the Ministry of Education, Science and Technology (grant number 2011-0006629).

\section{REFERENCES}

1. F. P. Bundy, H. T. Hall, H. M. Strong, and R. H. Wentorf, "Man Made Diamonds," Nature, 176 51-9 (1955).

2. M. N. Yoder "Diamond and Diamond-Like Films and Coatings," pp. 1-16, Plenum Press, New York, 1991.

3. L. Chn and Z. Fubao, "Effect of Soaking Time on the Friction Properties of Polycrystalline Diamonds," Int. J. Refract. Met. Hard Mater., 48 82-8 (2015).

4. H. Lu, J. Goldman, F. Ding, Y. Sun, M. X. Pulikkathara, V. N. Khabashesku, B. I. Yakobson, and J. Lou, "Friction and Adhesion Properties of Vertically Aligned Multiwalled Carbon Nanotube Arrays and Fluoro-Nanodiamond Films," Carbon, 46 [10] 1294-301 (2008).

5. L. Wang, Y. Gao, Q. Xue, H. Liu, and T. Xu, "Effects of Nano-diamond Particles on the Structure and Tribological Property of Ni-Matrix Nanocomposite Coatings," Mater. Sci. Eng. A, 390 [1-2] 3113-18 (2005).

6. T. Ohashi, W. Sugimoto, Y. Takasu, "Catalytic Etching of 100-Oriented Diamond Coating with $\mathrm{Fe}, \mathrm{Co}, \mathrm{Ni}$, and $\mathrm{Pt}$ Nanoparticles under Hydrogen," Diam. Relat. Mat., 20 [8] 1165-70 (2011).

7. T. Ohashi, W. Sugimoto, and Y. Takasu, "Catalytic Etching of Synthetic Diamond Crystallites by Iron," Appl. Sur. Sci., 258 [20] 8218-33 (2012)

8. H. Kishimoto, A. Suzuki, T. Shimonosono, M. E. Brito, K. Yamaji, T. Horita, F. Munakata, and H. Yokokawa, "Agglomeration Behavior of Nickel Particles on YSZ and $\mathrm{TiO}_{2}$-Doped YSZ Electrolytes," J. Power Sources, 199 17478 (2012).

9. J. H. Song and O. S. Song, "Surface Graphite Formation of the Brown Colored Type I Diamonds During High Pressure Annealing," J. Korean Ceram. Soc., 49 [6] 614-19 (2012).

10. A. C. Ferrari, "Raman Spectroscopy of Graphene and Graphite: Disorder, Elentron-Phonon Coupling, Doping and Nonadiabatic Effects," Solid State Commun., 143 [1-2] 47-57 (2007).

11. A. C. Ferrari, "Determination of Bonding in Diamond-Like Carbon by Raman Spectroscopy," Diam. Relat. Mat., 11 [36] 1053-61 (2002). 